1000

\section{TUBERCULOSIS RISK ASSESSMENT IN HOSPITAL} SETTINGS

'D Melo*, ${ }^{1} T$ Pinto, Â Rodrigues', ${ }^{1} \mathrm{E}$ Silva, ${ }^{1} \mathrm{M}$ Bastos, ${ }^{1} \mathrm{~L}$ Pires, ${ }^{1} \mathrm{AP}$ Sardo, ${ }^{1} \mathrm{~F}$ Mautempo. ${ }^{1}$ Occupational Health and Work Medicine Service; ${ }^{2}$ Risk Management Office, Centro Hospitalar do Baixo Vouga, Aveiro, Portugal

\subsection{6/oemed-2018-ICOHabstracts.598}

Introduction Tuberculosis (TB) is an occupational hazard for healthcare workers. National and internationals policies establish occupational TB risk assessment through the number of patients with TB per year for the whole facility. However, in an hospital setting with different workplaces, it's important to independently classify $\mathrm{TB}$ risk in every work environment in order to implement cost-effective preventive measures.

Methods We establish a TB risk matrix for our 500-beds hospital and we applied it retrospectively to each department from 2014 to 2016. We studied the following variables: frequency (number of inpatients with infectious TB per service per year), exposure (period of time without isolation measures per patient or, in case of outpatient setting, performance of high-risk procedures for transmission) and severity of the occupational disease.

Results The highest risk of occupational TB was found through the studied years in Emergency, Pneumology and Infectiology Departments. However, there was a decrease in the last year due to better isolation measures. Internal Medicine and Otorhinolaryngology wards were considered very high-risk departments due to prolonged exposure to TB patients without any control procedures. Imageology and Primary Care ward were consistently classified as high-risk as result of the high number of TB patients assisted. Exceptionally, in 2015, Intensive Care and Stroke units as well as Psychiatry department were found to have very high-risk TB infection due to a prolonged admission of one patient without isolation procedures. The other departments were classified as moderate or low risk.

Discussion All healthcare institutions should conduct TB risk assessment periodically as risk classification may change. These results allow to identify which departments have high-risk of occupational TB infection, in order to undertake specific preventive strategies and TB screening accordingl.

\section{FUNGAL KERATITIS IN AUXILIARY GARBAGE COLLECTOR AS AN OCCUPATIONAL DISEASE. CASE REPORT}

BS Sanchez ${ }^{*}$, Y Contreras, S Avelar, P Hurtado. UIDAC, Research Unit, Teaching and Clinical Support in Occupational Health, IMSS, Guadalajara, Mexico

\subsection{6/oemed-2018-ICOHabstracts.599}

Introduction Infectious keratitis is a serious ocular pathology with potentially catastrophic visual results, being this one of the most prevalent causes of irreversible blindness worldwide, according to the $\mathrm{WHO}$, with a prevalence ranging from $6 \%$ to $60 \%$, predominantly in developing countries.

Methods 45 years old man worker, with history of myopia with contact lens wear for 3 year, urban waste collector since 3 years and 9 months ago, without personal protection equipment, while, working had a right eye exposure from a garbage bag that was being compressed in a collecting truck, rubbing his eye immediately and removing contact lenses
5 hours later. One day later, he presented decreased visual acuity, hyperemic conjunctiva and leukoma, appearing to the ophthalmologist who indicated moxifloxacin ophthalmic, presenting partial recovery of visual acuity. 15 days later he continued with leukoma, which yielded to treatment with fluconazole, but the evolution continued with sudden decrease in vision 20/400, establishing diagnosis of $5 \times 4 \mathrm{~mm}$ corneal ulcer, receiving treatment with a patch of cyanoacrylate and a bandage lens on 3 occasions without improvement, requiring corneal transplantation performed 8 months later.

Results Direct fundoscopy, Goldmann lens: papilla with excavation of $0.4 \times 0.4 \mathrm{~mm}$, central emergency vessels, slimmed vascular pattern, cornea with central opacity at stromal oedema expenses and corneal centre ulcer of $5 \times 4 \mathrm{~mm}$.

Discussion During garbage collection workers are exposed to biological agents such as Aspergillus, Fusarium and Candida from organic materials; That without the use of appropriate personal protective equipment and combined with the use of contact lenses increases the risk of developing ocular pathologies such as fungal keratitis. Through symptomatology, physical exploration, and evolution of the pathology, the causal relationship was corroborated, cause-effect, work-injury, being determined as if occupational disease.

\section{THERE'S A RAT IN THE LAB - RAT BITE AND RAT BITE FEVER IN THE OCCUPATIONAL HEALTHCARE SETTING}

WLC Van Hooste*. MD, Mediwet Occupational Health Services, External Service for Prevention and Protection at Work, Ghent, Belgium

\subsection{6/oemed-2018-ICOHabstracts.600}

Introduction Ratborne diseases are a.o. leptospirosis, hantavirosis, tulaeremia, plague, rickettsiosis, pasteurellosis, rat bite fever and parasitical infections. Up to 10 percent of all ratbites results in 'rat bite fever' (RBF). RBF is a designation for 2 diseases caused by different gram negative bacteria: streptobacillary RBF, by Streptobacillus moniliformis, a rod-shaped bacteria and less common spirillary RBF or 'sodoku', by Spirillum minor, a spiral-shaped bacteria which occurs more in Asia (Japan). Streptobacillary RBF presents as a local skin lesion, followed abruptly by flu-like illness with fever, chills, headache, vomiting, pain of joints or muscles about 3-10 days after the initial injury. Within 2-4 days a diffuse maculopapular or petechial rash involving the extremities, especially palms and soles, appears. Transmission occurs by a bite or scratch of a rodent or predator of rats, as well as by ingestion of food or water contaminated by a rat. Ingestion leads to the gastrointestinal form of disease known as 'Haverhill fever', characterised by pharyngitis and vomiting. Relapsing fever and polyarthritis develop in 30 and 50 percent respectively.

Methods We studied the literature from the past 100 years to search for the occupational risk factors of rat bites and rat bite fever.

Result Numerous laboratories use rats as experimental animals, so we retrieved numerous cases from the lab. Other occupations at risk were pest control workers, cleaning workers, manual labourers in a warehouse, pet stores employees, veterinarians and vet personnel, farmers and rat breeders. As pet rats are becoming more popular, RBF rates are rising.

Discussion Ratbites are probably underreported. The diagnosis of RBF can be challenging and easily be overlooked. Unspite 